\title{
Association of cerebral palsy with consanguineous parents and other risk factors in a Palestinian population
}

\author{
S. Daher ${ }^{1,2}$ and L. El-Khairy ${ }^{1,3}$
}

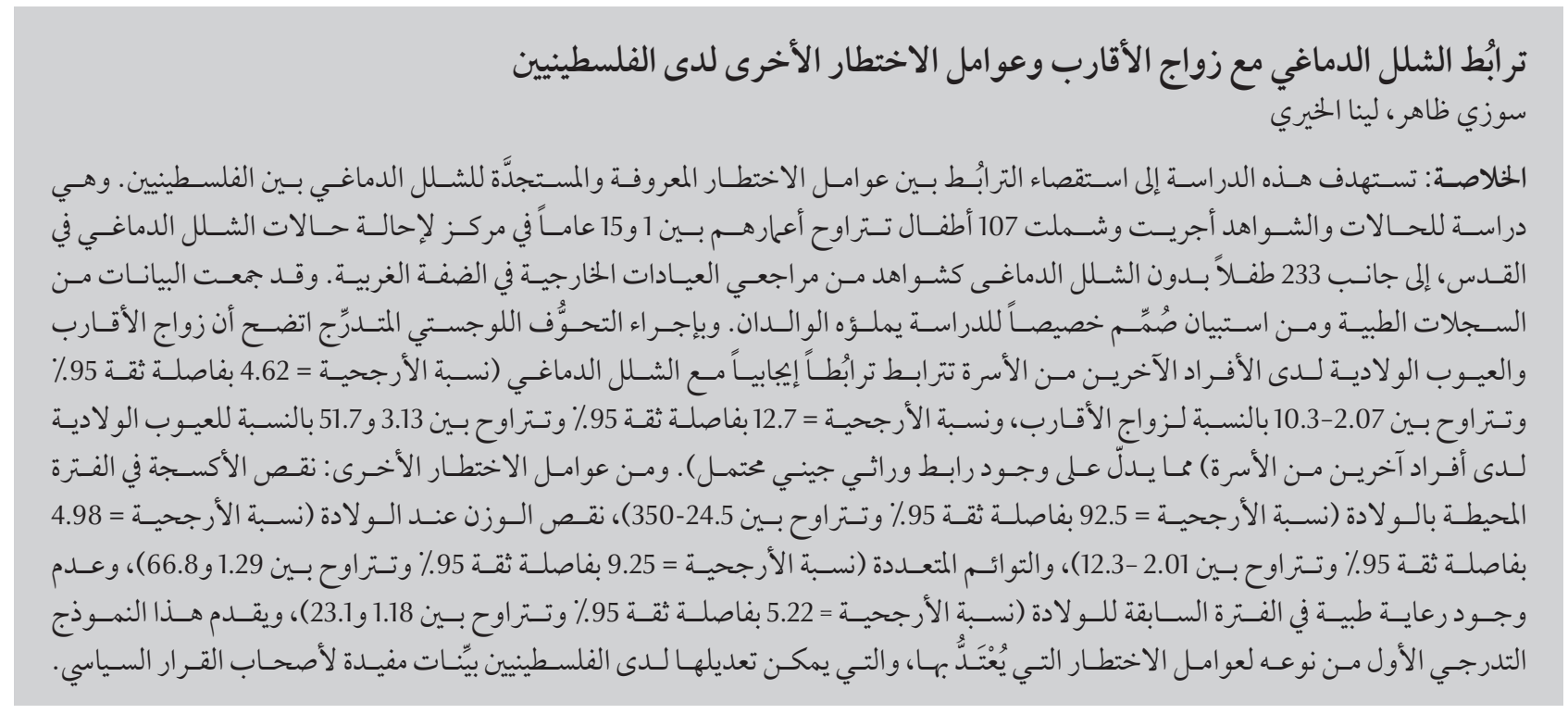

ABSTRACT This case-control study investigated risk factors for cerebral palsy in a Palestinian population. Cases were 107 children aged 1-15 years at a cerebral palsy referral centre in Jerusalem; controls were 233 children without cerebral palsy from West Bank outpatient clinics. Data were collected from medical records and a structured questionnaire to parents. In stepwise logistical regression, consanguinity and birth deficits in other family members were positively associated with cerebral palsy $(\mathrm{OR}=4.62 ; 95 \% \mathrm{Cl}: 2.07-10.3$ and $\mathrm{OR}=12.7 ; 95 \% \mathrm{Cl}: 3.13-51.7$ respectively), suggesting a possible genetic link. Other risk factors were: perinatal hypoxia $(\mathrm{OR}=92.5 ; 95 \% \mathrm{Cl}$ : 24.5-350), low birth weight $(\mathrm{OR}=4.98 ; 95 \% \mathrm{Cl}$ : 2.01-12.3), twin births $(\mathrm{OR}=9.25 ; 95 \% \mathrm{Cl}: 1.29-66.8)$ and no prenatal medical care $(\mathrm{OR}=5.22 ; 95 \% \mathrm{Cl}$ : 1.18-23.1). This first stepwise model of significant and modifiable risk factors in our population provides useful evidence for policy-makers.

Association de l'infirmité motrice cérébrale chez l'enfant, de la consanguinité chez les parents et d'autres facteurs de risque dans une population palestinienne

RÉSUMÉ La présente étude cas-témoins a étudié les facteurs de risque d'infirmité motrice cérébrale dans une population palestinienne. Le groupe de cas était composé de 107 enfants âgés de 1 à 15 ans consultant dans un centre d'orientation-recours pour l'infirmité motrice cérébrale à Jérusalem et celui des témoins de 233 enfants non affectés par cette pathologie et ayant eu recours à des services de consultations externes en Cisjordanie. Les données ont été recueillies à partir des dossiers médicaux et d'un questionnaire structuré administré aux parents. À l'analyse de régression logistique par étapes, la consanguinité et les anomalies congénitales chez d'autres membres de la famille étaient positivement associées à l'infirmité motrice cérébrale $(O R=4,62$; IC à $95 \%$ : 2,07-10,3 et $O R=12,7$; IC à $95 \%: 3,13-51,7$ respectivement), suggérant qu'un lien génétique était possible. D'autres facteurs de risque significatifs étaient les suivants : hypoxie périnatale $(O R=92,5$; IC à $95 \%: 24,5-350)$, faible poids de naissance $(O R=4,98$; IC à $95 \%: 2,01-12,3)$, naissances gémellaires $(O R=9,25 ;$ IC à $95 \%: 1,29-66,8)$ et absence de soins médicaux prénatals (OR = 5,22 ; IC à $95 \%$ : 1,18-23,1). Ce premier modèle par étape pour les facteurs de risque importants et modifiables dans notre population fournit des informations utiles pour les responsables de l'élaboration des politiques.

'School of Public Health, Al-Quds University, Abu Dies Campus, Jerusalem (Correspondence to S. Daher: Sdhaher@bethlehem.edu). ${ }^{2}$ Faculty of Nursing and Health Science, University of Bethlehem, Bethlehem, Palestine. ${ }^{3}$ Faculty of Nursing, Pharmacy and Health Professions, Birzeit University, Birzeit, Palestine.

Received: 29/09/13; accepted: 03/02/14 


\section{Introduction}

Cerebral palsy is the most common motor disability of childhood (1). It is caused by damage to the developing brain resulting in neurological and motor deficits. In adulthood mortality and morbidity from ischaemic heart disease, cerebrovascular disease, cancer and trauma are higher in people with cerebral palsy than in the general population (2). The underlying causes of the condition remain under debate and vary from medical mismanagement at birth to multifactor steps which form a series of causal pathways (3). Limited research also suggests that there are population-specific factors which may produce unique risks (4). Better evidence about the contribution made by both known and emerging risk factors are important for prevention of the disorder.

Having consanguineous parents is a known risk factor for congenital disability and genetic disorders (5). Although the worldwide prevalence of cerebral palsy has remained stable at 2-2.5 per 1000 live births (4), there are no population-based birth prevalence studies among highly consanguineous populations. It is estimated that onefifth of the world's population located in the Middle East, West Asia and North Africa and in emigrant populations now living in North America, Europe and Australia are consanguineous. A study conducted in Palestine in 2004 found that the rate of consanguinity was $45 \%$ of all marriages (6). Other estimated prevalence rates in the region are $68 \%$ in Egypt, 33\% in Syrian Arab Republic, $58.1 \%$ in Jordan, $54.4 \%$ in Kuwait, $57.7 \%$ in Saudi Arabia and 50.5\% in the United Arab Emirates (7). Despite this, studies into consanguinity and health in the region are limited. A study of Turkish children with cerebral palsy found consanguinity to be a top risk factor (8). This association of consanguinity with complex disorders such as cerebral palsy is new and the results are ambiguous (9). Some authors suggest consanguinity increases susceptibility to multifactorial diseases in addition to increased risks for autosomal recessive diseases compared with the general population (7). A more recent Jordanian study which examined global developmental disorders including cerebral palsy found that consanguinity was a major risk factor (9). Other evidence for developmental problems linked to consanguinity have been provided from the Syrian Arab Republic (10). A study in Palestine found higher reading disabilities in children with consanguineous parents $(6,11)$. However, other risk factors of importance for cerebral palsy in the region have been suggested, such as hypoxia, low birth weight, jaundice and preterm birth $(8,12)$.

Both cerebral palsy and consanguinity are public health issues in Palestine. This research - the first known study in Palestine-adds to the existing information and highlights an important health problem. This study aimed to examine the association of cerebral palsy with known and emerging risk factors, including consanguinity, in Palestinian children in order to present a model of the salient risk factors for Palestine.

\section{Methods}

\section{Study design and setting}

A case-control study design was used. The cases were selected from The Princess Basma Centre for the Disabled, Mount of Olives, Jerusalem, which is the national cerebral palsy rehabilitation centre for Arab children. Children under the age of 15 years are admitted free of charge for a period of 1 week to 3 months, depending on need. It is the only centre in Palestine which offers residential physiotherapy, special education, speech therapy, nursing services, social work and play. The unique holistic approach means that cases are referred by the Palestinian Ministry of Health $(\mathrm{MOH})$, United Nations Relief and
Work Agency for Palestine Refugees in the Near East (UNRWA) and private clinics. Therefore, cases came from all over Palestine. The controls were selected from West Bank outpatient clinics and were matched to cases based on the same geographical location of residence.

The study was carried out from 19 January to 29 August 2011. A consent form was signed by all participants and permission for the study was obtained from Al-Quds University institutional review board and all the health-care providers.

\section{Sample}

The sample size was determined using the following case-control sample size equation:

$$
N=\left(p_{0} q_{0}+p_{1} q_{1}\right)\left(Z_{1-\alpha / 2}+Z_{1-\beta}\right)^{2} /\left(p_{1}-p_{0}\right)^{2}
$$

where: $p_{1}=$ proportion of exposure among cases; $p_{0}=$ proportion of exposure among controls; $q_{1}=1-p_{1} ; q_{0}$ $=1-p_{0} ; \alpha=0.05 ; \beta=0.2-$ power of $80 \%$, based on the relative risk of the exposure and size of sample from existing published studies. This was combined with the desired power of the statistical test (13): $p_{0}=0.049, p_{1}=0.049 \times 3.4(\mathrm{RR})$ $=0.1666$. From this, $N=105$ for both cases and controls.

Males and females aged between $1-15$ years were included in this study. The diagnostic criteria for cases were a physician's diagnosis of cerebral palsy and physician-documented risk factors in the patients' records. From those resident at the Princess Basma Centre during the research period, a convenience sample of 107 cases with their mothers were recruited. The controls were selected by systematic probability sampling from every other child attending outpatient clinics on the day of the research visit, with any diagnosis except cerebral palsy. Clinics were chosen randomly from $\mathrm{MOH}$ and UNWRA registries; private clinics 
are not registered so local physicians were asked to identify suitable clinics in the different geographical locations. A total of 223 controls were included as cerebral palsy is a rare condition so a 1:2 ratio of cases to controls was used; 92 (41\%) controls were recruited from $\mathrm{MOH}$ clinics, 22 (10\%) from private and 109 (49\%) from UNRWA clinics in the West Bank. The location of the clinics were classified into north, middle and south region in line with the administrative divisions of the Palestinian Authority and controls were matched to cases in terms of geographical location of residence. Any cases or controls whose medical documentation was absent were excluded. There were 13 case exclusions due to omissions in their files. None of the cases refused to participate and 3 of the controls declined.

\section{Data collection}

Data were collected in the same way for cases and controls using a structured questionnaire (Daher $S$, unpublished questionnaire, 2011) that was filled by the investigator from data in the medical records and an interview with mothers in Arabic. This included demographic data of the parents, characteristics of the pregnancy and delivery, and information about the child including the child's diagnosis (the distribution, tone and severity of cerebral palsy).

\section{Variables}

Through a PubMed literature search in January 2011, known risk factors for cerebral palsy were identified and a list of variables was drawn up as the basis for the questionnaire. Data on the following variables were obtained from the children's medical records: place of delivery [Palestinian Authority Ministry of Health hospital (MOH), private or nongovernment hospital (NGO), Palestinian Red Crescent hospital]; type of delivery [trauma, normal spontaneous vaginal delivery, instrument assisted (forceps, vacuum), breech birth, caesarean section; reason for caesarean]; prematurity (no/yes; exact gestational age); multiple pregnancies (no/yes); vanishing twin (no/ yes); perinatal hypoxia (no/yes); low birth weight $(<2500 \mathrm{~g} /<1500$ g; exact weight); incubation (no/yes; length of time); postnatal problems (haemorrhage/bleeding; other to be specified); perinatal jaundice (no/yes; bilirubin levels; documented length of time with jaundice); and congenital abnormalities (no/yes). Data on other relevant variables were obtained from interviews with mothers: parents' age (mother and father); parents' education (classified according to local examinations: below tawghi, tawghi, college diploma, university); parents' socioeconomic status [occupation of father and mother: initially classified using the International Standard Classification of Occupations 2008 (14) and grouped into professional, skilled, semiskilled, unemployed]; consanguineous parents (no/yes; 1st cousins, 2nd cousins, more distant family relations); any close or extended family members with physical or cognitive deficits from birth (no/ yes; disability to be specified); fertility treatment (type to be specified); and thrombophilia/clotting disorder (no/ yes). All variables except sociodemographic variables were defined using Taber's cyclopedic medical dictionary (15).

\section{Validation}

Discussions as to the content and format of the questionnaire took place with multidisciplinary professionals who work at the hospital. A pilot study was used to verify that the questions were clear, the duration of the questionnaire was reasonable and that the questions, although of a personal nature, were not embarrassing. The questions appeared to have face validity; this was judged to be the case after the pilot study. As a result of the pilot study a question regarding the families' income was removed, as there was no objective way of verifying this. Socioeconomic status was therefore evaluated based on education and father's profession. The questionnaire was reviewed by 1 specialist paediatricians in the field of cerebral palsy and 2 general practitioners to judge the content validity. The use of medical records was important for criterion validity. The structure and content of medical records were similar for cases and controls, incorporating standardized patient record forms and documentation. Medical records were cross-checked with the information given. Consanguinity data was reliant on the mothers' reporting, but as such a marriage is considered normal no stigma would deter honest responses. All interviews we conducted by the first author and the use of medical records may have been beneficial in minimizing recall bias and any interviewer bias.

\section{Statistical analysis}

The data were first analysed by descriptive statistics including means and standard deviation (SD) and percentages. The $t$-test was used to investigate the difference in means. Univariate analysis for single directional crude associations and the chi-squared test for cross-tabulation were used to investigate whether proportions across more than one category among 2 or more independent groups were the same. Fisher exact test was used for small numbers. Logistic regression was used to test relationships between 2 noncontinuous variables and for model building. Each variable was entered into a stepwise logistical regression and adjusted for all other variables in the study to ascertain if the variable was confounded. All analysis was conducted 2-tailed with $P \leq 0.05$ significant. As the study set out to find the most significant risk factors for Palestine and to build the first known model for Palestinians, interaction was not tested. The small numbers in the study and the lack of possibility for generalization also informed the decision not to focus on possible interactions. Statistical analysis 
was done using SPSS, version 19 statistical software.

\section{Results}

The demographic data for the 107 cases and 223 controls are presented in Table 1. There was no statistically significant difference between the mean age of the case and control groups $[3.87$ (SD 2.71 ) years and 4.17 (SD 3.94) years respectively] $(P=0.47)$. There were slightly more males than females in both groups (male:female ratio 1.18 for cases and 1.12 for controls). The great majority of mothers of both groups were housewives, and when mothers did work most were in professional employment. There was no statistically significant difference in the age of mothers or fathers comparing the case and the control groups.

Table 1 shows that significantly more of the cases than controls were born to parents who were 1st cousins (34.6\% versus $17.9 \%)$ or 2 nd cousins ( $8.4 \%$ versus $1.3 \%)(P<0.001)$. A family history of birth deficits was reported for $15(14.0 \%)$ cases and 4 (1.8\%) controls.

Table 2 shows the birth characteristics of the cases and controls. There was a statistically significant difference between the mean weight of cases and controls at delivery, with the cases having lower birth weight [2686 (SD 902) g versus 3183 (SD 600) g] $(P<0.001)$. Mean gestational age was significantly lower in cases than controls [36.4 (SD 5.2) weeks versus 38.5 (SD 2.2) weeks] $(P<0.001)$. Over half of the cases (58.9\%) were incubated after delivery compared with only $6.3 \%$ of controls and the mean time spent under incubation was significantly longer for cases. Jaundice was noted for $18.7 \%$ of cases versus $7.6 \%$ of controls and the duration of jaundice was significantly longer for cases.

A high proportion of the cases were delivered by caesarean section (48,

\begin{tabular}{|c|c|c|c|c|c|}
\hline \multirow{2}{*}{$\begin{array}{l}\text { Variable } \\
\text { Child's age (years) [mean (SD)] }\end{array}$} & \multicolumn{2}{|c|}{$\begin{array}{c}\text { Cases } \\
(n=107)\end{array}$} & \multicolumn{2}{|c|}{$\begin{array}{l}\text { Controls } \\
(n=223)\end{array}$} & \multirow{2}{*}{$\begin{array}{c}\boldsymbol{P} \text {-value } \\
0.47^{\mathrm{a}}\end{array}$} \\
\hline & 3.87 & $(2.71)$ & 4.17 & $(3.94)$ & \\
\hline Child's sex (no., \%) & & & & & $0.83^{\mathrm{a}}$ \\
\hline Male & 58 & 54.2 & 118 & 52.9 & \\
\hline Female & 49 & 45.8 & 105 & 47.1 & \\
\hline Region of residence (no., \%) & & & & & $0.45^{\mathrm{a}}$ \\
\hline North & 43 & 40.2 & 88 & 39.5 & \\
\hline Middle & 53 & 49.5 & 101 & 45.3 & \\
\hline South & 11 & 10.3 & 34 & 15.2 & \\
\hline Mother's age (years) [mean (SD)] & 27.5 & (6.3) & 27.1 & (6.3) & $0.588^{\mathrm{b}}$ \\
\hline Father's age (years) [mean (SD)] & 33.0 & $(7.0)$ & 32.9 & $(7.4)$ & $0.908^{b}$ \\
\hline Mother's occupation (no., \%) & & & & & $0.47^{\mathrm{a}}$ \\
\hline Professional & 5 & 4.7 & 16 & 7.2 & \\
\hline Skilled & 3 & 2.8 & 7 & 3.1 & \\
\hline Unskilled & 0 & 0.0 & 2 & 0.9 & \\
\hline Unemployed/ housewife & 99 & 92.5 & 198 & 88.8 & \\
\hline Father's occupation (no., \%) & & & & & $<0.05^{\mathrm{a}}$ \\
\hline Professional & 20 & 18.7 & 34 & 15.2 & \\
\hline Skilled & 26 & 24.3 & 59 & 26.5 & \\
\hline Unskilled & 43 & 40.2 & 86 & 38.6 & \\
\hline Unemployed & 12 & 11.2 & 43 & 19.3 & \\
\hline Parents' consanguinity (no., \%) & & & & & $<0.001^{\mathrm{a}}$ \\
\hline Not related & 56 & 52.3 & 169 & 75.8 & \\
\hline 1st cousins & 37 & 34.6 & 40 & 17.9 & \\
\hline 2nd cousins & 9 & 8.4 & 3 & 1.3 & \\
\hline More distant family related & 5 & 4.7 & 11 & 4.9 & \\
\hline Family history of birth deficits ( ${ }^{\mathrm{c}}$ (n., \%) & 15 & 14.0 & 4 & 1.8 & \\
\hline
\end{tabular}

${ }^{a}$ Chi-squared test; ${ }^{b}$-test; ${ }^{c}$ Any close or extended family members with physical or cognitive deficits from birth. $S D=$ standard deviation. 


\begin{tabular}{|c|c|c|c|c|c|}
\hline \multirow{2}{*}{$\begin{array}{l}\text { Variable } \\
\text { Gestational age (weeks) [mean (SD)] }\end{array}$} & \multicolumn{2}{|c|}{$\begin{array}{c}\text { Cases } \\
(n=107)\end{array}$} & \multicolumn{2}{|c|}{$\begin{array}{l}\text { Controls } \\
(n=223)\end{array}$} & \multirow{2}{*}{$\begin{array}{l}\boldsymbol{P} \text {-value } \\
<0.001^{\mathrm{a}}\end{array}$} \\
\hline & 36.4 & $(5.2)$ & 38.5 & $(2.2)$ & \\
\hline Premature (<37 weeks) (no., \%) & 35 & 32.7 & 32 & 14.3 & $<0.001^{\mathrm{a}}$ \\
\hline Birth weight (g) [mean (SD)] & 2686 & $(902)$ & 3183 & $(600)$ & $<0.001^{\mathrm{a}}$ \\
\hline Low birth weight $(<2500$ g) (no., \%) & 41 & 38.3 & 17 & 7.7 & $<0.001^{\mathrm{a}}$ \\
\hline Perinatal jaundice (no., \%) & 20 & 18.7 & 17 & 7.6 & $<0.001^{\mathrm{a}}$ \\
\hline Duration of jaundice (days) [mean (SD)] & 2.29 & $(6.85)$ & 0.65 & $(3.90)$ & $<0.05^{\mathrm{b}}$ \\
\hline Incubated (no., \%) & 63 & 58.9 & 14 & 6.3 & $<0.001^{\mathrm{a}}$ \\
\hline Duration of incubation (days) [mean (SD)] & 15.4 & $(23.2)$ & 0.8 & $(5.1)$ & $<0.001^{\mathrm{b}}$ \\
\hline
\end{tabular}

${ }^{a}$ Chi-squared test; ${ }^{b}$ t-test.

$S D=$ standard deviation .

44.9\%) compared with only 58 (26.0\%) of the controls. The reasons for caesarean section differed between cases and controls. For infants with cerebral palsy most of the caesarean deliveries were due to long labour, premature rupture of membranes, multiple births and fetal distress. For the controls the reasons included having all previous deliveries by caesarean section, loss of amniotic fluid, no contractions and the health of the mother. More of the control mothers $(17.8 \%)$ were aware of the reason for their caesarean section than were case mothers (7.3\%).

Table 3 shows the regression analysis for parents' consanguinity (1st or 2nd cousins) and other relations (more distantly related members of the same family). Cousin consanguinity was a significant risk factor for cerebral palsy $(\mathrm{OR}=3.23$; 95\% CI: 1.93-5.39) $(P$ $<0.001$ ), whereas more distant family relations was not a significant risk.

Table 4 summarizes the univariate analysis for all the study variables.
Pregnancy and delivery variables that were significantly associated with a higher risk of cerebral palsy were: birth weight $\leq 2500 \mathrm{~g}(\mathrm{OR}=4.60)$; caesarean section delivery $(\mathrm{OR}=2.65)$; gestational age < 37 weeks $(\mathrm{OR}=2.90)$; multiple births $(\mathrm{OR}=11.4)$; infection during pregnancy $(\mathrm{OR}=4.80)$; infection during delivery $(\mathrm{OR}=5.00)$; congenital abnormalities $(\mathrm{OR}=2.41)$; and hypoxia at birth $(\mathrm{OR}=65.8)$. Other factors that were significantly associated with cerebral palsy were: no medical care during pregnancy $(\mathrm{OR}=$ 5.50); and delivery in $\mathrm{MOH}$ hospital $(\mathrm{OR}=2.70)$.

Having consanguineous parents increased the risk of cerebral palsy almost 3 -fold $(\mathrm{OR}=2.85)$ and having other children with disabilities in the family increased it almost 9-fold $(\mathrm{OR}=8.90)$ (Table 4). The numbers of cases and controls with a family history of birth deficits were small, but of the 15 case children with disabilities in other family members 6 also had cerebral palsy in the family, all from consanguineous parents. For the controls only 4 children had cases of disability in the family: 2 were cerebral palsy, 1 was postnatally acquired and 1 was due to hypoxia during delivery.

The main risk factors for cerebral palsy were found by using a stepwise regression model (Table 5). All risk factors were entered individually in order of significance and removed if significance was lost. The coefficient in the analysis remained constant showing that there were no extraneous variables confounding the result. Of the 6 factors which remained out of all the study variables entered into the model, perinatal hypoxia was associated with the highest risk (adjusted OR $=92.5$; 95\% CI: 24.5-350). Two family variables were significant risks for cerebral palsy: consanguineous parents $(\mathrm{aOR}=4.62 ; 95 \%$ CI: 2.07-10.3); and presence of birth deficits in other family members (aOR $=12.7 ; 95 \%$ CI: 3.13-51.7). Other risk factors that remained significant in the final model were: low birth weight $(\mathrm{aOR}=4.98 ; 95 \% \mathrm{CI}: 2.01-12.3)$;

\begin{tabular}{|c|c|c|c|c|c|c|}
\hline \multirow[t]{2}{*}{ Degree of parents' relatedness } & \multicolumn{2}{|c|}{$\begin{array}{c}\text { Cases } \\
(n=107)\end{array}$} & \multicolumn{2}{|c|}{$\begin{array}{l}\text { Controls } \\
(n=223)\end{array}$} & \multirow[t]{2}{*}{ OR $(95 \% \mathrm{Cl})$} & \multirow[t]{2}{*}{$P$-value } \\
\hline & No. & $\%$ & No. & $\%$ & & \\
\hline Not related & 56 & 52.3 & 169 & 75.8 & (ref.) & \\
\hline Consanguineous (1st or 2 nd cousins) & 46 & 43.0 & 43 & 19.3 & $3.23(1.93-5.39)$ & 0.001 \\
\hline More distant family related & 5 & 4.7 & 11 & 4.9 & $1.38(0.46-4.11)$ & 0.573 \\
\hline
\end{tabular}

(ref.) = reference category; $O R=$ odds ratio; $C I=$ confidence interval. 


\begin{tabular}{|c|c|c|c|c|c|}
\hline \multirow[t]{2}{*}{ Variable } & \multicolumn{2}{|c|}{$\begin{array}{c}\text { Cases } \\
(n=107)\end{array}$} & \multicolumn{2}{|c|}{$\begin{array}{l}\text { Controls } \\
(n=223)\end{array}$} & \multirow[t]{2}{*}{ OR $(95 \% \mathrm{Cl})$} \\
\hline & No. & $\%$ & No. & $\%$ & \\
\hline \multicolumn{6}{|l|}{ Birth weight (g) } \\
\hline$>2500$ & 72 & 67.3 & 205 & 92.3 & (ref.) \\
\hline$\leq 2500$ & 35 & 32.7 & 17 & 7.7 & $4.60(2.60-8.14)^{\mathrm{b}}$ \\
\hline \multicolumn{6}{|l|}{ Delivery } \\
\hline Spontaneous vaginal & 51 & 55.1 & 163 & 74 & (ref.) \\
\hline Caesarean section & 48 & 44.9 & 58 & 26.0 & $2.65(1.61-4.34)^{\mathrm{b}}$ \\
\hline \multicolumn{6}{|l|}{ Perinatal hypoxia } \\
\hline No & 58 & 54.2 & 219 & 98.2 & (ref.) \\
\hline Yes & 49 & 45.8 & 4 & 1.8 & $65.8(22.4-193)^{\mathrm{b}}$ \\
\hline \multicolumn{6}{|l|}{ Gestation (weeks) } \\
\hline $38-42$ & 70 & 67.3 & 191 & 85.7 & (ref.) \\
\hline$<37$ & 35 & 32.7 & 32 & 14.3 & $2.90(1.67-5.03)^{\mathrm{b}}$ \\
\hline \multicolumn{6}{|l|}{ Perinatal jaundice } \\
\hline No & 87 & 81.3 & 205 & 92.3 & (ref.) \\
\hline Yes & 20 & 18.7 & 17 & 7.7 & $2.70(1.39-5.55)^{\mathrm{a}}$ \\
\hline \multicolumn{6}{|l|}{ Multiple births } \\
\hline Singleton & 97 & 90.7 & 221 & 99.1 & (ref.) \\
\hline Multiple (twins) & 10 & 9.3 & 2 & 0.9 & $11.4(2.45-53.0)^{\mathrm{b}}$ \\
\hline \multicolumn{6}{|l|}{ Congenital abnormalities } \\
\hline None & 97 & 90.7 & 222 & 99.6 & (ref.) \\
\hline Congenital abnormality, other & 1 & 0.9 & 0 & 0.0 & $2.41(1.31-4.44)^{b}$ \\
\hline Congenital abnormality, cleft palate & 6 & 5.6 & 0 & 0.0 & \\
\hline Congenital abnormality, head malformation & 3 & 2.8 & 1 & 0.4 & \\
\hline \multicolumn{6}{|l|}{ Infection during pregnancy } \\
\hline No & 87 & 81.3 & 213 & 95.5 & (ref.) \\
\hline Yes & 20 & 18.7 & 10 & 4.5 & $4.80(2.20-10.9)^{b}$ \\
\hline \multicolumn{6}{|l|}{ Infection during delivery } \\
\hline No & 98 & 91.6 & 219 & 98.2 & (ref.) \\
\hline Yes & 9 & 8.4 & 4 & 1.6 & $5.00(1.51-16.7)^{\mathrm{a}}$ \\
\hline \multicolumn{6}{|l|}{ Prenatal care } \\
\hline Yes & 95 & 88.8 & 218 & 97.8 & (ref.) \\
\hline No & 12 & 11.2 & 5 & 2.2 & $5.50(1.89-16.1)^{\mathrm{b}}$ \\
\hline \multicolumn{6}{|l|}{ Family history of birth deficits ${ }^{a}$} \\
\hline No & 92 & 86 & 219 & 98.2 & (ref.) \\
\hline Yes & 15 & 14.0 & 4 & 1.8 & $8.90(2.89-27.6)^{\mathrm{b}}$ \\
\hline \multicolumn{6}{|l|}{ Consanguineous parents } \\
\hline No & 56 & 52.3 & 169 & 75.8 & (ref.) \\
\hline Yes & 51 & 47.7 & 54 & 24.2 & $2.85(1.75-4.64)^{\mathrm{b}}$ \\
\hline \multicolumn{6}{|l|}{ Mother's age (years) } \\
\hline $22-38$ & 85 & 78.7 & 163 & 70.4 & (ref.) \\
\hline$<21$ & 20 & 19.0 & 46 & 21.7 & $0.84(0.47-1.53)$ \\
\hline$>39$ & 2 & 2.3 & 14 & 7.9 & $0.27(0.06-1.23)$ \\
\hline \multicolumn{6}{|l|}{ Father's age (years) } \\
\hline $22-38$ & 86 & 80 & 165 & 72.7 & (ref.) \\
\hline$<21$ & 1 & 1.1 & 6 & 3.3 & $0.33(0.39-2.74)$ \\
\hline$>39$ & 20 & 18.9 & 52 & 24.0 & $0.74(0.41-1.32)$ \\
\hline
\end{tabular}




\begin{tabular}{|c|c|c|c|c|c|}
\hline \multirow[t]{2}{*}{ Variable } & \multicolumn{2}{|c|}{$\begin{array}{c}\text { Cases } \\
(n=107)\end{array}$} & \multicolumn{2}{|c|}{$\begin{array}{l}\text { Controls } \\
(n=223)\end{array}$} & \multirow[t]{2}{*}{ OR $(95 \% \mathrm{Cl})$} \\
\hline & No. & $\%$ & No. & $\%$ & \\
\hline \multicolumn{6}{|l|}{ Place of delivery } \\
\hline NGO/private hospital & 40 & 37.4 & 137 & 61.7 & (ref.) \\
\hline MOH hospital & 67 & 62.6 & 85 & 38.3 & $2.70(1.69-4.38)^{\mathrm{b}}$ \\
\hline \multicolumn{6}{|l|}{ Place of delivery } \\
\hline MOH/NGO hospital & 90 & 87.4 & 180 & 65.1 & (ref.) \\
\hline Private hospital & 13 & 12.6 & 43 & 34.9 & $0.58(0.30-1.13)$ \\
\hline \multicolumn{6}{|l|}{ Place of delivery } \\
\hline $\mathrm{MOH} /$ private hospital & 80 & 75.5 & 128 & 58.8 & (ref.) \\
\hline Other/NGO hospital & 26 & 24.5 & 91 & 41.2 & $0.46(0.27-0.78)^{\mathrm{b}}$ \\
\hline
\end{tabular}

${ }^{a} P<0.05 ;{ }^{b} P<0.01$.

(ref.) = reference category; $O R=$ odds ratio; $C I=$ confidence interval; $M O H=$ Ministry of Health;

$\mathrm{NGO}=$ nongovernmental organization (Makassad and Hilal hospitals).

multiple births (twins) $(\mathrm{aOR}=9.25$; 95\% CI: 1.29-66.8); and no prenatal medical care $(\mathrm{aOR}=5.22 ; 95 \% \mathrm{CI}$ : $1.18-23.1)$

\section{Discussion}

This study has produced the first model of risk factors for cerebral palsy among Arab children from the West Bank and Jerusalem. The main findings of this study are that crude associations were significant for many known and emerging population-specific risk factors for cerebral palsy. When adjusted for all variables with elimination of confounding variables we found that perinatal hypoxia, low birth weight, multiple births (twins), no prenatal medical care, other birth deficits in the family and consanguinity remained as significant risk factors.

Among the known risk factors for cerebral palsy, one of the first to be discussed in the literature was caesarean section, which is considered protective or associated with a slight rise in risk (16). In the present study $45.3 \%$ of the cases had been born by caesarean section compared with $26.3 \%$ of controls, and this was significant in the univariate analysis ( $\mathrm{OR}=2.65$; $95 \%$ CI: 1.61-4.34). However, the variable was not retained in the final regression model. All parents were asked the reason for the caesarean section, and of particular interest is the high number of mothers, particularly among cases, who were unaware of the reason. Indeed $10 \%$ more of the cases did not know why their child had been delivered by caesarean. In Palestine this is a decision taken by the doctor; there are no elective caesarean sections at 39 weeks of gestation as is common in other countries (17). It should be remembered that with any observational study the data were collected post hoc and therefore we cannot know if the association was due to poor medical management and not a common, unknown confounding factor. How many cases were due to suboptimal obstetric response (not expediting delivery) is not known. Clinical signs sufficient to warrant a caesarean section may only be recognizable after the damage has occurred. Offering mothers caesarean section at 39 weeks is not currently available as a birthing plan in Palestine.

The strongest association with cerebral palsy in our study was with perinatal hypoxia. Hypoxia was documented for $45.8 \%$ cases and $1.8 \%$ of controls and this was the most important risk factor that remained in the final multiple regression model (OR $=92.5$; 95\% CI:
24.5-350). Lack of oxygen is believed to be an important and preventable cause of cerebral palsy and for many years no research was done to look at other risk factors for cerebral palsy (18). Indeed this belief underpinned much of the justification for the practice of fetal monitoring in labour and the increase in caesarean section rates.

No medical care in pregnancy was another new, previously unresearched risk factor. With no national health system in Palestine, whether, when and how a woman seeks medical care in pregnancy is solely in the control of the individual. As primary health care in Palestine is available and is not expensive the reasons why $11.2 \%$ and $2.2 \%$ of case and control mothers respectively did not having regular prenatal checkups are not known and requires further investigation. Lack of regular prenatal check-ups was a significant risk factor for cerebral palsy in the multiple regression analysis $(\mathrm{OR}=5.22 ; 95 \% \mathrm{CI}$ : 1.18-23.1). From this association we can assume that the benefits of routine ultrasound in early pregnancy and other checks are important for prevention. We could not identify any studies to compare with this result.

The mean birth weight of cases and controls were $2686 \mathrm{~kg}$ and $3183 \mathrm{~kg}$ respectively, and low birth weight $(\leq 2500$ 


\begin{tabular}{|c|c|c|}
\hline Risk factor & Adjusted OR ${ }^{\mathrm{a}}(95 \% \mathrm{Cl})$ & $P$-value \\
\hline Perinatal hypoxia & $92.5(24.5-350)$ & $<0.001$ \\
\hline Family history of birth deficits & $12.7(3.13-51.7)$ & $<0.001$ \\
\hline Multiple birth (twins) & $9.25(1.29-66.8)$ & 0.027 \\
\hline No prenatal medical care & $5.22(1.18-23.1)$ & 0.029 \\
\hline Low birth weight & $4.98(2.01-12.3)$ & 0.001 \\
\hline Consanguineous parents & $4.62(2.07-10.3)$ & $<0.001$ \\
\hline Delivery at NGO hospital & $0.38(0.16-0.91)$ & 0.030 \\
\hline
\end{tabular}

adjusted for all variables in the study.

$O R=$ odds ratio $; \mathrm{Cl}=95 \%$ confidence interval; $\mathrm{NGO}=$ nongovernmental organization (Makassad and Hilal hospitals).

g) was another significant variable in the final regression model $(\mathrm{OR}=4.98 ; 95 \%$ CI: 2.01-12.3). Different explanations can be suggested for this association of low birth weight with cerebral palsy: first, that low birth weight and cerebral palsy is an epiphenomenon; secondly, that intrauterine growth restriction causes the conditions responsible for brain damage; thirdly, that growth restriction or low birth weight makes the child more vulnerable to hypoxia; and finally that the damage has already occurred and that low birth weight is related to earlier pregnancy factors such as malformations or viral infections. The underlying mechanisms are unclear (18).

Another significant variable in the risk of cerebral palsy was multiple births, found in 10 (9.3\%) case and 2 (0.9\%) control mothers (all the multiple births were twins, no higher order births). Despite the small numbers twin births proved to be a significant risk at all levels of analysis and remained in the regression model $(\mathrm{OR}=9.25 ; 95 \% \mathrm{CI}$ : 1.29-66.8). Multiple births have greater risks of complications particularly for the second-born child. Further they have been shown to be associated with low birth weight, preterm delivery and death of the co-fetus (19).

Another of the variables we studied-family members with birth deficits - was defined to include any close or extended family members with physical or cognitive deficits from birth. Due to this wide definition the possibility of confounding factors cannot be overlooked. This association was found to be significant, with $14.0 \%$ of cases and $1.8 \%$ of controls having other family members with birth deficits, a variable which was highly significant in the multiple regression analysis (OR $=12.7 ; 95 \%$ CI: 3.13-51.7). As part of family history it may encompass a range of influences, direct and less direct, genetic factors or maybe intergenerational environmental effects. Further research is needed with perhaps a more specific definition. Other studies which focused on the risk of a second child having cerebral palsy where one child had already been diagnosed produced an OR of 1.6 of recurrence (20).

The etiology of cerebral palsy may vary between countries, and therefore population-specific factors of cultural relevance such as consanguinity are important to investigate. One of the main objectives of our study was to see if there was an association between cerebral palsy and consanguinity. The results of the study showed that $47.7 \%$ of cases versus $24.2 \%$ of controls were from consanguineous parents (1st or 2 nd cousins) and this was an important variable remaining in the regression model $(\mathrm{OR}=4.62$; 95\% CI: 2.07-10.3). In other published research consanguinity was also found to be among the top risk factors (8). The results of our study provides some evidence of a genetic etiology for cerebral palsy. More research into possible genetic links with cerebral palsy will improve our understanding of the pathophysiology of the disorder. The significance of emerging risk factors can be explained by the belief that well-known risk factors do not present the full picture of etiology. Consanguinity is a social issue which needs to be addressed by government and nongovernment agencies, and there is a need for awareness through education. For many populations inter-marriage has a number of perceived benefits, for example, keeping money in the family and families being known to each other (21). Available research into a genetic link to cerebral palsy is mostly in the form of small-scale studies and case reports $(22,23)$. Most estimates place the proportion of cerebral palsy cases with genetic etiology at between $1 \%$ and $2 \%$, and it has been argued that cerebral palsy could be both genetic in origin as well as the result of environmental insult at any point during central nervous system development (24). With $60 \%$ of cerebral palsy cases having an unknown cause other than suspected prepartum risk factors (25) means this area warrants attention, especially in countries with a large consanguineous population. Small-scale studies have identified nonsense mutations (26) and for consanguineous populations there may be genes which have temporal or site-specific targets that act on the developing brain. At present access to genetic diagnostic testing is limited. There are at least 20 different syndromes associated with cerebral palsy (23) and it is possible there are more genetic syndromes which remain undiagnosed.

The results of this study have many similarities with an Egyptian study conducted in 2011, in which the most significant risk factors for cerebral palsy were found to be low birth weight, preterm birth, hypoxia and consanguineous marriage (12). In that study preterm 
birth lost significance in the stepwise model, as did other known risk factors such as parents' socioeconomic status.

The importance of this study is that it is the first known study in Palestine identifying risk factors for Palestinian children. There are no known case-control studies or other comparable studies in the region. Subsequent studies with more power would provide more information about the factors investigated here. Identifying modifiable factors leads to the possibility of prevention. The study has provided some evidence for the need for heightened awareness about the link between consanguinity and cerebral palsy. This requires a cultural change perhaps realized through health promotion incorporating advice from health providers and social marketing campaigns. Deep-seated cultural practices are obviously hard to change and require time.

Our results concerning perinatal hypoxia suggest that when a case of cerebral palsy is identified at birth there is a need for an in-hospital inquiry aimed at possible improvement of birth practices for future avoidance. Our study also highlighted the need for greater regular prenatal check-ups. This requires an educational change so that mothers are made aware of the importance of visits for their health and their baby's health.

\section{Limitations}

As this was a small-scale study we cannot state any claim to generalizability of the results and a study with a larger sample is needed. Concerning bias the population was a homogenous group with controls representative of cases in terms of geographical area of residence. This was important to increase representativeness as convenience sampling in one treatment centre was used to recruit cases. How many Palestinian children do not access any services, and their location of residence, remains unknown, as there is no cerebral palsy register, but this is acknowledged as a limitation in terms of the representativeness of the study. Also all the limitations that accompany an observational case-control study need to be borne in mind. Incidence/ prevalence bias should be considered, because the use of incident cases rather than prevalent cases is deemed better in case-control studies, although this may not be applicable to cerebral palsy which by definition is non-progressive. In addition, this research incorporated a non-standardized questionnaire as a means of data collection, crossedchecked with medical records, which pose a weakness in terms of reliability and validity. Information bias is also a possibility with any case-control study; however, there was only the possibility of recall bias for demographic variables. There are no standardized questionnaires in existence that address the areas of our study, and there is no national cerebral palsy register in Palestine. Selection bias is always a concern in casecontrol studies so it needs to be noted that the researchers had no control over who would be treated at The Princess Basma Centre. The research continued until the sample size had been achieved. This study was unique; with no registers available data collection options are limited. Adjustment was made for gestation, sex and all study variables to avoid confounding. For the factors which this paper addresses the possibility of bias is considered minimal.

\section{Conclusions}

To conclude, among several otherknown risk factors such as perinatal hypoxia and multiple births, consanguinity of parents was significantly associated with cerebral palsy in Palestinian children.

\section{Acknowledgements}

This research does not represent the views of any institution or funding body. Funding: This research received no outside funding.

Competing interests: None declared.

\section{References}

1. Suvanand S, Kapoor SK, Reddaiah VP, Singh U, Sundaram KR. Risk factors for cerebral palsy. Indian J Paediatr. 1997;64(5):677-85.

2. Shankaran S. Prevention, diagnosis and treatment of cerebral palsy in near-term and term infants. Clin Obstet Gynaecol. 2008;51(4):829-39. PMID:18981806

3. Keogh JM, Badawi N. The origins of cerebral palsy. Curr Opin Neurol. 2006 Apr;19(2):129-34. PMID:16538085

4. Stanley F, Blair E, Alberman E, editors. Cerebral palsies: epidemiology and causal pathways. Cambridge: Cambridge University Press; 2000.

5. Hamamy H. Consanguineous marriages, preconception consultations in primary health care settings. J Community Genet. 2012 Jul;3(3):185-92. PMID:22109912

6. Assaf S, Khawaja M. Consanguity trends and correlates in the Palestinian Territories. J Biosoc Sci. 2009 Jan;41(1):107-24. PMID:18549512
7. Hamamy H, Antonarakis SE, Cavalli-Sforza LL, Temtamy S, Romeo G, Kate LP, et al. Consanguineous marriages, pearls and perils: Geneva International Consanguinity Workshop Report. Genet Med. 2011 Sep;13(9):841-7. PMID:21555946

8. Erkin G, Delialioglu SU, Ozel S, Culha C, Sirzai H. Risk factors and clinical profiles in Turkish children with cerebral palsy: analysis of 625 cases. Int J Rehabil Res. 2008 Mar;31(1):89-91. PMID:18277211

9. Masri A, Hamamy H, Khreisat A. Profile of developmental delay in children under five years of age in a highly consanguineous community: a hospital-based study-Jordan. Brain Dev. 2011 Nov;33(10):810-5.

10. Othman H, Saadat M. Prevalence of consanguineous marriages in Syria. J Biosoc Sci. 2009 Sep;41(5):685-92. PMID:19433003

11. Abu-Rabia S, Maroun L. The effect of consanguineous marriage on reading disability in the Arab community. Dyslexia. 2005 Feb;11(1):1-21. PMID:15747804 
12. El-Tallawy HN, Farghaly WM, Shehata GA, Metwally NA, Rageh TA, Abo-Elfetoh N. Epidemiology of cerebral palsy in El-Kharga District-New Valley (Egypt). Brain Dev. 2011 May;33(5):406-11. PMID:20797827

13. Chapter 8. Case-control studies: planning and execution. In Kelsey JL Whittemore AS, Evans AS, Thompson WD, editors. Methods in observational epidemiology. 2nd ed. Oxford: Oxford University Press; 1986.

14. International Standard for Classification of Occupations [website]. Geneva: International Labour Organization; 2008 (http://www.ilo.org/public/english/bureau/stat/isco/index. htm, accessed 27 April 2014).

15. Taber's medical dictionary. 11th ed. Philadelphia (PA): FA Davis Company; 1970.

16. Gilles MT, Blair E, Watson L, Badawi N, Alessandri L, Dawes V, et al. Trauma in pregnancy and cerebral palsy: is there a link? Med J Aust. 1996 Apr 15;164(8):500-1. PMID:8614347

17. O'Brien JR, Usher RH, Maughan GB. Causes of birth asphyxia and trauma. Can Med Assoc J. 1966 May 21;94(21):1077-85. PMID:5933054

18. Nelson KB. The epidemiology of cerebral palsy in term infants. Ment Retard Dev Disabil Res Rev. 2002;8(3):146-50. PMID:12216058

19. Petterson B, Nelson KB, Watson L, Stanley F. Twins, triplets, and cerebral palsy in births in Western Australia in the 1980s. BMJ. 1993 Nov 13;307(6914):1239-43. PMID:8281055
20. Hemminki K, Li X, Sundquist K, Sundquist J. High familial risks for cerebral palsy implicate partial heritable etiology. Paediatr Perinat Epidemiol. 2007 May;21(3):235-41. PMID:17439532

21. Barbour B, Salameh P. Consanguinity in Lebanon; prevalence, distribution and determinants. J Biosoc Sci. 2009 Jul;41(4):50517. PMID:19175949

22. McHale DP, Mitchell S, Bundey S, Moynihan L, Campbell DA, Woods CG, et al. A gene for autosomal recessive symmetrical spastic cerebral palsy maps to chromosome 2q24-25. Am J Hum Genet. 1999 Feb;64(2):526-32. PMID:9973289

23. Menkes J, Flores-Sarnat L. Cerebral palsy due to chromosomal anomalies and continuous gene syndrome. Clin Perinatol. 2006;33:481-501. PMID:16765733

24. Kuban K, Leviton A. Cerebral palsy. N Engl J Med. 1994; 330:188-95.

25. Barnes C, DeVaber G. Prothombicabnormalities in childhood ischemic stroke. Thromb Res. 2006;118:67-74. PMID:16039697

26. Verschuuren-Bemelmans CC, Winter P, Sival DA, Elting JW, Brouwer OF, Müller U. Novel homozygous ALS2 nonsense mutation (p.Gln715X) in sibs with infantile-onset ascending spastic paralysis: the first cases from northwestern Europe. Eur J Hum Genet. 2008 Nov;16(11):1407-11. PMID:18523452 